\title{
CARDIAC REHABLLITATION IN HEART FAILURE. PART II. DOES HIIHER INTENSITY MEANS BETTER OUTCOME?
}

\author{
Agnieszka Kujawska, 1, A, B, D Radosław Perkowski, 1, B, D Natalia Skierkowska, ${ }^{1, B, D}$ \\ Weronika Topka, ${ }^{1, B, D}$ Małgorzata Gajos, 1, B, D Joanna Androsiuk-Perkowska, 1, B, D \\ Aleksandra Cieślińska, ${ }^{1, B, D}$ Beata Przybysz, ${ }^{2, B, D}$ Dobrawa Kwolik, ${ }^{2, B, D}$ \\ Dominika Siekacz, 2, B, D Dominika Rybarczyk, 2, B, D Sławomir Kujawskij, B, D
}

\author{
${ }^{1}$ Faculty of Health Sciences, Department and Clinic of Geriatrics, Nicolaus Copernicus University \\ ${ }^{2}$ Kazimierz Wielki University, Bydgoszcz, Poland \\ ${ }^{3}$ Faculty of Health Sciences, Department of Hygiene, Epidemiology and Ergonomics, Division of Ergonomics and Exercise Physiology, \\ Nicolaus Copernicus University

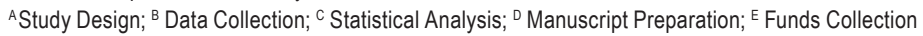 \\ Address for corpespondence: \\ Agnieszka Kujawska \\ Department of Geriatrics \\ Marii Skłodowskiej Curie 9, 85-094 Bydgoszcz, Poland \\ E-mail: agajos11@gmail.com
}

\begin{abstract}
Ahstract Heart failure (HF) due to its universality has become a huge challenge for modern medicine. Second part of the twentieth century brought significant changes in the rehabilitation, diagnostic and pharmacological procedures. There are no definitive guidelines for Cardiac Rehabilitation (CR) in HF. Based on previous studies, the article tried to describe and illustrate the mechanism of effective CR and its intensity in HF patients, which could be helpful in CR protocol development.

Cardiac Rehabilitation has confirmed efficacy in increased physical level of participation in inter alia, home/work/recreational activities, improved psychosocial well-being, functional independence, prevention of disability, long-term adherence to maintaining physically active lifestyle, improved cardiopulmonary fitness, strength, muscle endurance, and flexibility, reduced cardiovascular events risk and risk of mortality.

Before and after CR conduction, baseline and final aerobic capacity should be examined with an ergospirometry test to evaluate $\mathrm{CR}$ protocol intensity and check its effectiveness, respectively. Frequency of training-bouts in CR protocol in HF patients were from 3 to 7 days per week, intensity ranged from 40 to $80 \% \mathrm{VO}_{2}$ max or 9 to 14 on rating of the perceived exertion (RPE) scale or 6 to 20 on the Borg scale. Duration of single bout-exercise ranged from 20 to 60 minutes.
\end{abstract}

Key Wordls cardiac rehabilitation, physical exercise, heart failure, aerobic training, resistance training 


\section{Introduction}

\section{Cardiac rehabilitation and heart failure}

Heart failure (HF) due to its universality has become a huge challenge for modern medicine. Second part of the twentieth century brought significant changes in the rehabilitation, diagnostic and pharmacological procedures. Cardiac Rehabilitation (CR) is the gold standard in care of patients with heart diseases (Blumenthal et al., 2016).

$\mathrm{CR}$ programs are based on the patient's clinical status, with three phases included most often. Phase 1 is an inpatient program which should be started soon after the acute cardiac event or intervention. The main goal is to mobilize elderly HF patients. Patients in phase 2 have three training bouts per week, for a total of 36 sessions over a period of 3-4 months. Training protocol includes simple home-based, self-supervised programs or with telephone electrocardiographic (ECG) monitoring. Phase 3 refers to non-ECG-monitored programs utilities, without medical supervision or fitness facilities included (Balady et al., 2011).

Comprehensive rehabilitation is designed to help the patient to return to full physical activity and to reduce cardiovascular events. Cardiac rehabilitation should be started as soon as possible after stabilization of the patient, even during he/she is in intensive care. Depending on the functional state of the patient, further stages of physical activity should increases which could facilitate a faster recovery (Smarż, 2008). However, it is worth paying attention to the contradictions list to take part in $\mathrm{CR}$, which are presented in Table 1.

\section{Methods of capdiopulmonary assessment in HF patients}

To evaluate HF patients readiness to take the physical effort, at least one pre-test should be assessed. In case of aerobic capacity, there are few methods used in clinical examination.

One of the cost-free functional tests is the six-minute walking test (6MWT) (Lipkin, Scriven, Crake, PooleWilson, 1986). Result of this test is the number of meters walked in six minutes. The patient should be asked to walk as fast as he/or she is able to, reminding that they ought to maintain the same velocity during the whole test. Patients should be reminded about the duration of the test and ask to think about the walk velocity which he or she is able to maintain during this time. Patients should walk alone, if not, sufficient time interval between examination of the next patient have been maintained to exclude the competition factor. Some studies (Roomi et al., 1996) showed that creating competitive conditions can increase mean results of patients in this test up to $30 \%$, comparing to group without such conditions. If necessary, physician can walk behind the patients for the whole test time. Practice time before actual test should be provided. Moreover, mean result for this test was reported to be 631 meters and was 84 meters greater in men compared to women, results were based on 51 healthy subjects aged 50-85 (Troosters, Gosselink, Decrame, 1999). Moreover, obtained result in the 6MWT could have a prognostic value (Rostagno et al., 2003).

Cardiopulmonary exercise stress testing (CPX) is a gold standard in the maximal aerobic capacity assessment. It provides several physiological parameters derived from cardiac system (through ECG) and ventilatory system, some are based on calculations based on parameters from both systems (i.e. $\mathrm{O}_{2}$ pulse, which is a report between $\mathrm{O}_{2}$ uptake and heart rate $\left(\mathrm{VO}_{2} / \mathrm{HR}\right)$. Ventilatory system parameters are, i.a., maximal oxygen consumption $\left(\mathrm{VO}_{2} \mathrm{max}\right)$, production of the carbon dioxide per unit of time (VCO), ventilatory exchange (VE), respiratory exchange ratio (RER). The rate of the maximal oxygen consumption $\left(\mathrm{VO}_{2} \mathrm{max}\right)$ is traditionally expressed as milliliters per minute or as milliliters per kilogram per minute and is affected by age, gender, body weight, muscle mass, and conditioning 
status. $\mathrm{VO}_{2}$ max adjusted to the lean body mass obtained During CPX test elevated the prognostic value of CPX test in the assessment of patients with chronic HF (Osman, Mehra, Lavie, Nunez, Milani, 2000; Weber, Janicki, 1985).

Decreased $\mathrm{VO}_{2}$ max was estimated as a significant predictor of the mortality, moreover increasing of the VE/ $\mathrm{VCO}_{2}$ slope is a good predictor as well (Francis et al., 2000).

The use of $<19 \mathrm{ml}_{2} / \mathrm{kg}$ of lean body mass/min could serve as a cut-off point which could serve in determination of the transplantation schedule, particularly in women and the obese (Osman et al., 2000). Corra, Mezzani, Bosimini, Giannuzzi (2004) have developed an algorithm for the risk stratification procedure with symptom-limited CPX in chronic HF patients. An algorithm is based on a multiparametric decoding scrutiny incorporating the stepwise implementation of the following parameters: $\mathrm{Vo}_{2} \mathrm{max}, \mathrm{VE} / \mathrm{VCO} 2$ slope, and RER max (Corra et al., 2004).

Interestingly, exercise echocardiography testing combined with CPX testing could serve as a best method in the determination of effort intolerance in HF patients (Shimiaie et al., 2015).

Table 1. Absolute and relative contraindications for exercise training in HF patients (adapted from Adsett, Mullins, 2010)

Absolute contraindications

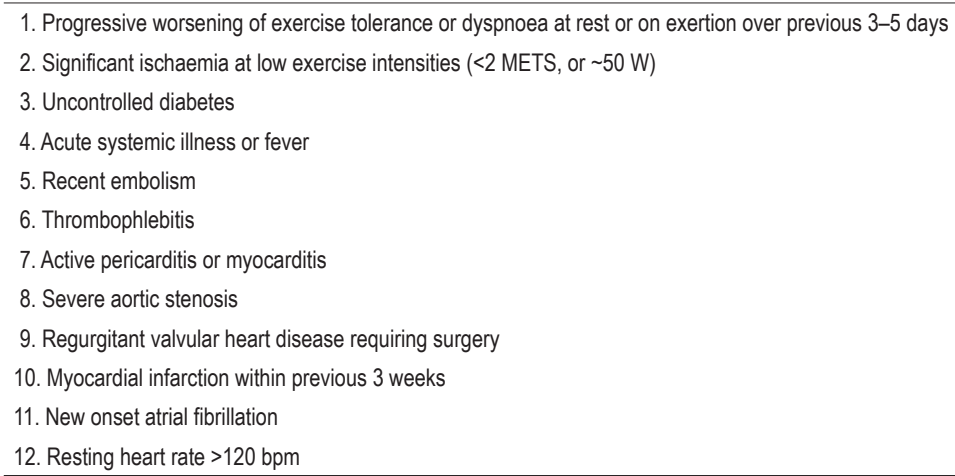

Relative contraindications

1. $\geq 2 \mathrm{~kg}$ increase in body mass over previous $1-3$ days

2. Concurrent continuous or intermittent dobutamine therapy

3. Decrease in systolic blood pressure with exercise

4. New York Heart Association Functional Class IV

5. Complex ventricular arrhythmia at rest or appearing with exertion

6 . Supine resting heart rate $\geq 100 \mathrm{bpm}$

7. Pre-existing co-morbidities

8. Moderate aortic stenosis

9. $\mathrm{BP}>180 / 110 \mathrm{mmHg}$ (evaluated on a case by case basis)

\section{Cardiac Rehabilitation protocol - aerobic training}

Low or moderate exercise intensity is recommended for patients with HF. It improves maximal oxygen uptake, exercise tolerance and quality of life, and also reduces hospitalization and mortality (Benito, Nattel, 2009).

A randomized-controlled trial have shown that 2 months of the moderate exercise can improve $\mathrm{VO}_{2}$ max by 18\% (Belardinelli, Georgiou, Cianci, Purcaro, 1999). 
In 2004, a meta-analysis of 9 randomized controlled trials of ExTraMATCH involving 801 people with HF (395 people taking rehabilitation, 406 served as a control group) demonstrated a $35 \%$ decrease in mortality and a $30 \%$ decrease in re-hospitalization in people after 2 years of rehabilitation (Piepoli, Davos, Francis, Coats, 2004).

It is worth noting that exercise intolerance in HF patients contributes to the continuous deterioration of health: skeletal muscle weakness and walking disorders, among others (Keast et al., 2013). Nordic Walking could serve as an effective and above all a safe activity with positive effect mainly on the circulatory system and respiratory system. Recent studies show that the use of Nordic Walking as an intervention in HF patients has shown that after a 12 -week workout the functionality has increased by $18 \%$, estimating by a 6MWT. A significant group of people with heart disease may experience depressive symptoms. These symptoms can contribute to adverse complications. After the 12-week intervention the symptoms of depression measured by Hamilton Rating Scale for Depression have decreased noticeably (Keast et al., 2013).

Prospective randomized study evaluated the effect of exercise training on left ventricular function (LV) and haemodynamic response in patients with chronic HF (Hambrecht et al., 2000). The study involved 73 men aged 70 years with chronic heart failure (LV ejection fraction circa 0.27 ). Both groups underwent echocardiography and exercise tests at baseline and after 6 months. Patients were asked to engage in the activities that will increase their heart rate for 20 minutes each day for 6 months. In addition, they attend in at least 1 training bout lasting 60 minutes in each week. Exercise protocols included walking, strengthening exercises and ball games. Patients assigned to the control group continued their individualized cardiac medication and were supervised by physicians. Three key conclusions were drawn during the study. First, aerobic endurance training leads to increased LV stroke during rest and during exercise and to slight but significant decrease in diameter and end-diastolic volume. Moreover, long-term training exercises are associated with significant reductions of the TPR at rest. In addition, a significant correlation was estimated between vascular endothelial vascular improvement and TPR decrease during exercise. Third, changes in TPR were associated with changes in cardiac output and end-diastolic diameter (Hambrecht et al., 2000).

In randomized controlled trial from 2007, twenty-seven HF patients with standard pharmacological treatment (LV ejection fraction $29 \%, \mathrm{VO}_{2}$ max $13 \mathrm{~mL} / \mathrm{kg} / \mathrm{min}$ ) were randomized to either medium-intensive continuous training (70\% HRmax) or aerobic interval training (95\% of HRmax), 3 bouts of training for 12 weeks in total (Wisløff et al., 2007). There was a significant $46 \% \mathrm{VO}_{2}$ max improvement in intervention group, compared to $14 \%$ in the moderate continuous training group and was associated with reverse LV remodeling. Moreover, only the intervention group noted the reductions in the LV end-diastolic and end-systolic volumes. In addition, LV ejection fraction and mitochondrial function in lateral vastus muscle increased improved and intervention group (Wisløff et al., 2007).

In the study from 2011 (Edelmann et al., 2011) 64 HF patients were incorporated into intervention (exercise) or control (usual care) groups. Training protocol intensity increased: two bouts of aerobic per week, 20-40 min with $50-60 \%$ of $\mathrm{VO}_{2}$ max were conducted in the first 4 weeks of protocol. In the fifth week, the intensity of aerobic training protocol increased to $70 \% \mathrm{VO}_{2} \mathrm{max}$, resistance training was incorporated as well as. During the resistance training, subjects were doing 15 repetitions at one training bout 60 to $65 \%$ of their 1 repetition maximum. $\mathrm{VO}_{2}$ max and the score in the physical functioning questionnaire increased significantly in the intervention group compared to the control (Edelmann et al., 2011).

RCT with non-active control group on 2,331 patients with Left Ventricular Ejection Fraction (LVEF) $<35 \%$ induced training protocol consisted of 36 training-bouts (3-months, home exercises 5 time/week for 40 minutes, 
target HR was $60 \%$ HRR increased to $70 \%$ after patients adaptation to exercise). During follow-up a decrease in mortality $(-4 \%, p=0.7)$, cardiovascular mortality and hospitalization $(-8 \%, p=0.14)$, cardiovascular mortality and hospitalization for HF (-13\%, $p=0.06)$ was observed, comparing to the control group (O'Connor et al., 2009). These results were reexamined after adjusting for confounding factors such: baseline exercise duration, LVEF, depression severity and a history of cardiovascular conditions. Analysis revealed that the rate of total mortality or hospitalization $(-11 \%, P=0.03)$, cardiovascular mortality or hospitalization $(-9 \%, P=0.09)$, and cardiovascular mortality or cardiovascular hospitalization $(-15 \%, P=0.03)$ decreased, thus suggesting that exercise training had beneficial effects in patients with HF (O'Connor et al., 2009).

Adsett et.al. (Keast et al., 2013) recommended an interval training with using different modalities of motor patterns, i.a., cycle ergometer, treadmill, rowing machines, step aerobics, calisthenics; swimming and Tai Chi, 3-5 time/week, 50-70\% VO $\mathrm{VO}_{2}$ max or 60-80\% HRR; RPE between 9 and 14 on the Borg 6-20 scale, 10-20 min and progress to longer sessions 30-40 min (Adsett, Mullins, 2010).

Table 2. Protocols of cardiac rehabilitation including resistance exercise

\begin{tabular}{|c|c|c|c|c|c|c|c|c|c|}
\hline \multicolumn{10}{|c|}{ Resistance training } \\
\hline \multicolumn{2}{|l|}{ Author } & \multirow{2}{*}{$\begin{array}{c}\text { Adsett et al., } \\
2010 \\
-\end{array}$} & \multicolumn{3}{|c|}{ Piepoli et al., 2011} & \multirow{2}{*}{$\begin{array}{c}\text { Piña et al., } \\
2003 \\
-\end{array}$} & \multicolumn{2}{|c|}{ Selig et al., 2010} & \multirow{2}{*}{$\begin{array}{c}\text { Ades et al., } \\
2013 \\
-\end{array}$} \\
\hline Main goal & & & pretraining & $\begin{array}{c}\text { resistance } \\
\text { training }\end{array}$ & $\begin{array}{l}\text { strength } \\
\text { training }\end{array}$ & & NYHA class I-II & NYHA III-IV & \\
\hline \multirow{3}{*}{ Intensity } & $1 \mathrm{RM}$ & $60 \% 1 \mathrm{RM}$ & $<30 \% 1 \mathrm{RM}$ & $30-40 \% 1 \mathrm{RM}$ & $40-60 \% 1$ RM & - & - & - & - \\
\hline & Borg scale & $9-13$ & - & - & - & - & $6-20$ & $6-20$ & - \\
\hline & RPE & $6-20$ & $<12$ & $12-13$ & $<15$ & - & $11-14$ & $10-13$ & - \\
\hline \multicolumn{2}{|c|}{ Repetitions } & $8-15$ & $5-10$ & $12-25$ & $8-15$ & - & $6-15$ & $4-10$ & $10-12$ \\
\hline \multicolumn{2}{|l|}{ Sets } & $2-4$ & $\begin{array}{l}\text { 1-3 circuits/ } \\
\text { session }\end{array}$ & $\begin{array}{l}1 \text { circuit/ } \\
\text { session }\end{array}$ & $\begin{array}{l}1 \text { circuit/ } \\
\text { session }\end{array}$ & - & $\begin{array}{l}1-3 \\
4-8\end{array}$ & $\begin{array}{l}1-2 \\
3-4\end{array}$ & $1-2$ \\
\hline \multicolumn{2}{|c|}{ Frequency } & 1-2 days/wk & $2-3 /$ wk & $2-3 / w k$ & $2-3 / w k$ & - & 2-3days/wk & 2-3days/wk & 2-3 days/wk \\
\hline \multicolumn{2}{|l|}{ Duration } & $20-30 \mathrm{~min}$ & - & - & - & - & $\begin{array}{l}\text { Extra } 5 \text { min } \\
\text { stretch }\end{array}$ & - & - \\
\hline \multicolumn{2}{|c|}{$\begin{array}{l}\text { Additional } \\
\text { recommendation } \\
\text { proposed by author }\end{array}$} & $\begin{array}{l}\text { Avoid } \\
\text { isometric } \\
\text { exercises }\end{array}$ & \multicolumn{3}{|c|}{ Avoid Valsalva or abdominal straining } & $\begin{array}{l}\text { Elastic band } \\
\text { Repetitive } \\
\text { isolated } \\
\text { muscle } \\
\text { training }\end{array}$ & $\begin{array}{r}\text { Circuit weigh } \\
\text { TheraBand } \\
\text { Body weight } \\
\text { Different exercis } \\
\text { muscle g } \\
\text { For NYHA I-II } \\
\text { training stretchir } \\
\text { muscle g }\end{array}$ & $\begin{array}{l}\text { exercise } \\
\text { es for major } \\
\text { roup } \\
5 \text { min post- } \\
\text { g the major } \\
\text { roup }\end{array}$ & $\begin{array}{c}\text { Exercises } \\
\text { engaging } \\
\text { major } \\
\text { muscle } \\
\text { groups }\end{array}$ \\
\hline
\end{tabular}

Pina et.al. (Piña et al., 2003) showed that cardiac rehabilitation recommendation for HF patients are still not clear. Most safety options are aerobic exercises on treadmill and bicycle ergometry with frequency $3-5 \mathrm{~d} / \mathrm{wk}$ and walking on non-training days, $70-80 \% \mathrm{VO}_{2} \max ; 60-65 \% \mathrm{VO}_{2} \max$, Borg scale RPE of 12-13. During single training bout, 10-15 min should be spent for proper warm-up with 20-30 minutes of the main part and lastly, period of cool-down should be also included (Piña et al., 2003). Meta-regression analysis from 2016 (Uddin et al., 2016) on predictors of exercise capacity following exercise-based rehabilitation in patients with coronary heart disease and heart failure included trials in which exercise frequency ranged from 3 to 4 days per week (mean: 3,6), 
training bout duration ranged from 35 to 47 minutes (mean: 41 minutes), training protocol duration lasted from 22 to 31 months (mean: 27) and exercise intensity ranged from 50 to $85 \%$ of $\mathrm{Hrmax}$ and $\mathrm{VO}_{2}$ max (Uddin et al., 2016). Interestingly, low-intensity $\mathrm{CR}\left(40 \% \mathrm{VO}_{2} \max \right)$ for 8 wk, 3 days per week could be effective in some patients (Belardinelli, Georgiou, Scocco, Barstow, Purcaro, 1995).

\section{Cardiac Rehabilitation protocol - resistance training}

A CR typical exercise training session consists of three parts. First, 5 minutes of warm-up (stretching and light calisthenics, exercise training using light weights or exercise machines-biceps curls, triceps extensions, military presses, shoulder shrugs, bent-knee push-ups, bent-knee "crunches," and quarter squats, addressed to the major muscle groups). This part increase patients' ability to perform daily living and work (lifting and carrying). Second part includes 20 minutes of aerobic exercise training and third part 5-15 minutes of cool-down (Balady et al., 2011).

Additional strength training included into training protocol could lead to muscular strength and endurance in the exercise-trained muscle improvement.

Adsett et.al. recommended to avoid isometric exercises and used light weights only (Adsett, Mullins, 2010). Initial training bouts intensity should incorporate lifting weights of approximately $40 \%$ of one-repetition maximum (1 RM) then while patients exercise adaptations could increase to $60 \% 1 \mathrm{RM}$. Training protocol should incorporate 1-2 training bouts each week, with duration range of 20-30 min, and 2-4 sets for each exercise in a range of 8-15 repetitions (Adsett, Mullins, 2010).

Table 3. Protocols of cardiac rehabilitation including aerobic exercise

\begin{tabular}{|c|c|c|c|c|c|c|c|c|}
\hline \multicolumn{9}{|c|}{ Aerobic training } \\
\hline \multicolumn{2}{|l|}{ Authors } & Adsett et al., 2010 & $\begin{array}{l}\text { Piepoli et al., } \\
2011\end{array}$ & $\begin{array}{l}\text { Piña et al., } \\
2003\end{array}$ & Piña et al., 2003 & \multicolumn{2}{|c|}{ Selig et al.2010 } & $\begin{array}{l}\text { Ades et al., } \\
2013\end{array}$ \\
\hline \multicolumn{2}{|l|}{ Type } & $\begin{array}{l}\text { steady/intermittent/interval; } \\
\text { cycle ergometer, treadmill, } \\
\text { rowing machines, } \\
\text { step aerobics, calisthenics, } \\
\text { swimming and Tai Chi }\end{array}$ & $\begin{array}{l}\text { aerobic: } \\
\text { continuous } \\
\text { and interval }\end{array}$ & $\begin{array}{l}\text { Aerobic, } \\
\text { resistive } \\
\text { or both }\end{array}$ & $\begin{array}{l}\text { Treadmill, } \\
\text { bicycle } \\
\text { ergometry }\end{array}$ & \multicolumn{2}{|c|}{$\begin{array}{l}\text { Interval training: start } \\
1: 1, \text { progress to } 2: 1 \\
\text { exercise/rest ratio }\end{array}$} & - \\
\hline \multicolumn{2}{|c|}{ Frequency } & $3-5$ days/wk & $3-5$ days/wk & 3-5days/wk & $3-5$ days/wk & \multicolumn{2}{|c|}{ 4-7 days/wk } & 4 days/wk \\
\hline \multicolumn{2}{|c|}{$\begin{array}{l}\text { Patients classification on the } \\
\text { baseline }\end{array}$} & - & - & - & - & $\begin{array}{l}\text { NYHA } \\
\text { class I-II }\end{array}$ & $\begin{array}{c}\text { NYHA } \\
\text { class III-IV }\end{array}$ & $\begin{array}{c}3-7 \\
\text { MET-h/wk }\end{array}$ \\
\hline \multirow{4}{*}{ Intensity } & $\mathrm{VO}_{2} \max$ & $50-70 \%$ & $\begin{array}{l}40-50 \% \\
\text { to } 70-80 \%\end{array}$ & $60-80 \%$ & $70-80 \%$ & $\begin{array}{l}40-70 \%, \\
\text { to } 80 \%\end{array}$ & $40-60 \%$ & - \\
\hline & Heart Rate Reserve & $60-80 \%$ & & $60-70 \%$ & & $40-75 \%$ & $40-65 \%$ & $55-80 \%$ \\
\hline & RPE & $9-14$ & $<15$ & - & - & $11-14$ & $\leq 13$ & - \\
\hline & Borg Scale & $6-20$ & - & $13-14$ & $12-13$ & $6-20$ & - & $12-14$ \\
\hline \multicolumn{2}{|l|}{ Duration } & $\begin{array}{c}\text { Start } 10-20 \mathrm{~min} \text {, progress } \\
\text { to } 30-40 \mathrm{~min}\end{array}$ & $\begin{array}{l}\text { Start } 5-10 \mathrm{~min} \text {, } \\
\text { progress to } \\
20-60 \mathrm{~min}\end{array}$ & - & $\begin{array}{l}\text { Warm-up: } \\
\text { 10-15 min, } \\
\text { Aerobic: } 20- \\
30 \text { min, } \\
\text { Cool-Down }\end{array}$ & - & $\begin{array}{c}10-15 \mathrm{~min}, \\
\text { to } 45-60 \\
\text { min }\end{array}$ & $\begin{array}{l}>30 \mathrm{~min} / \\
\text { session }\end{array}$ \\
\hline \multicolumn{2}{|c|}{$\begin{array}{l}\text { Additional recommendation } \\
\text { proposed by Authors }\end{array}$} & Patients with higher risk & $\begin{array}{l}\text { Medical history } \\
\text { and patient } \\
\text { examination }\end{array}$ & $\begin{array}{l}\text { Individual } \\
\text { protocol }\end{array}$ & $\begin{array}{c}\text { Assessment } \\
\text { of functional } \\
\text { capacity }\end{array}$ & \multicolumn{2}{|c|}{$\begin{array}{l}\text { Individualized } \\
\text { approach }\end{array}$} & $\begin{array}{l}\text { Pretraining } \\
\text { exercise } \\
\text { testing }\end{array}$ \\
\hline
\end{tabular}




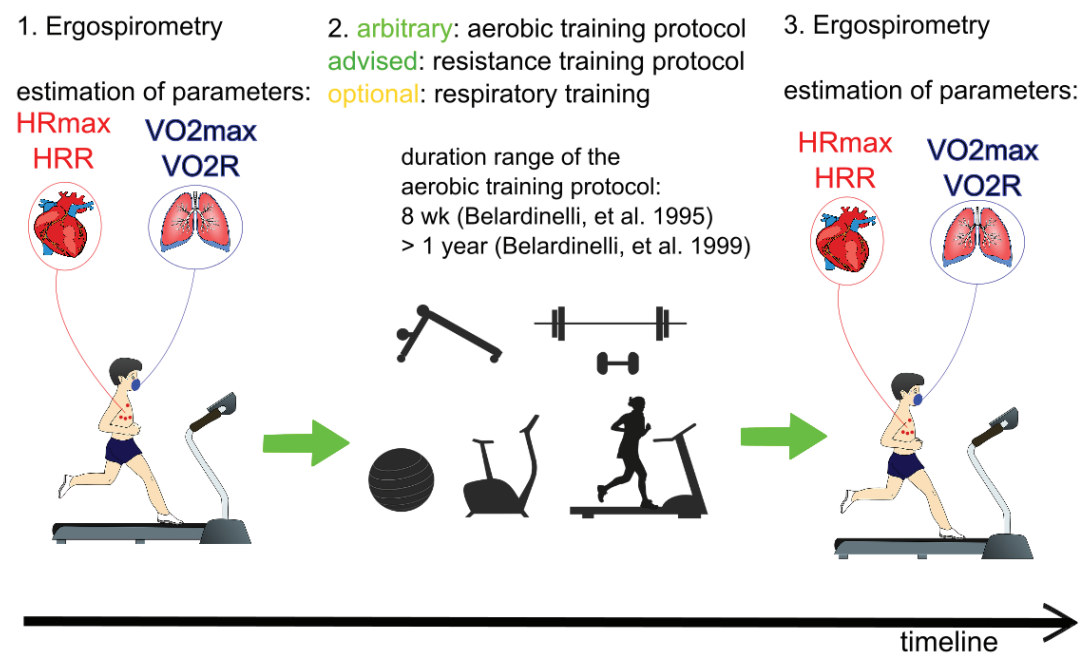

Figure 1. The timeline of the $\mathrm{CR}$

Figure 1 shows the timeline of the CR. Optimal duration of whole protocol is very crucial: as other noted (Adsett, Mullins, 2010) training cessation causes physiological functioning reverse, therefore optimal protocol duration should be established.

\section{Discussion}

Taking part in CR is not free from contradictions (Giannuzzi et al., 2001), nevertheless could effectively improve patient's health in many dimensions. Anderson et.al. in meta-analysis of 63 studies draw conclusions that $\mathrm{CR}$ induction reduces the cardiovascular mortality, hospital stay and improves a quality of life (Anderson et al., 2016). However, Piña et.al. (2003) showed that cardiac rehabilitation recommendations for HF patients are still not clear. The same Authors claim that safety and efficacy of resistance training has not been established, however exercise training using small free weights $(1,2$, or $5 \mathrm{lb})$, elastic bands, or repetitive isolated muscle training was proposed by Authors (Piña et al., 2003).

In general, aerobic exercise-training-bout in CR in above described researches lasted 20 minutes or longer (to maximum $60 \mathrm{~min}$ ) and were performed at $40 \%$ (Belardinelli et al., 1995) to $80 \% \mathrm{Vo}_{2} \mathrm{max}, 40 \%$ to $80 \%$ of the HRmax, frequency 3-7 days/wk (Adsett, Mullins, 2010; Piña et al., 2003; Piepoli, et al., 2011; Selig et al., 2010; Ades et al., 2013). Noteworthy, it is crucial to examine the aerobic capacity before CR initiation, while some patients require CR protocol with lower intensity (Balady et al., 2011). Results of study based on 12 weeks training of CR and $\mathrm{CR}$ with stress management training (SMT), show significant improvements in coronary heart disease biomarkers and lower event rates of the cardiovascular diseases (Blumenthal et al., 2016). Lower rates of clinical events was noted in a group with mixed CR and SMT. Result of this study shows a positive effect of CR on patients' health but also underlies the importance of the comprehensive cooperation with other individuals from medical team such as psychotherapist (Blumenthal et al., 2016). 
There are plenty of possible mechanism on level of systems, organs tissue and cells, by which CR can improve functioning of HF patients. CR, among other mechanisms, increases rest myocardial blood flow (Legallois et al., 2016), improves mean ratio of early to late mitral inflow velocities (Alves et al., 2012) decreases sympathetic tone while increasing parasympathetic tone of autonomic nervous system (Coats et al., 1992), decreases level of, inter alia, brain natriuretic peptide (Legallois et al., 2016), atrial natriuretic peptide and vasopressin, aldosterone (Braith, Welsch, Feigenbaum, Kluess, Pepine, 1999). There are also evidences that CR induction in patient with HF can improve cognitive functioning (Gunstad et al., 2005). That show us that it is still need for studies which examine the effectiveness of regarding a role and influence of CR on cognitive function (Gunstad et al., 2005).

In summary, CR should be based on comprehensive, interprofessional, individual approach to patient's needs, baseline patient assessment $\left(\mathrm{VO}_{2}\right.$ max and/or maximal strength test which is crucial in establishing training protocol intensity); nutritional counseling and cardiovascular risk factor management; psychosocial interventions; and physical activity and exercise training counseling. Before, during and after CR in HF patients HR, blood pressure, clinical signs/symptoms, ST-segment changes, hemodynamics, perceived exertion, exercise capacity should be controlled. Moreover, as Authors of review describe (Piña et al., 2003), respiratory training seems to be very promising tool in $\mathrm{CR}$ especially in those patients with additionally respiratory system issues. Indeed, as results of meta-analysis shows (Montemezzo, Fregonezi, Pereira, Britto, Reid, 2014), inspiratory muscle training elicits greater improvement in patients with inspiratory muscle weakness.

There are many studies confirming the effectiveness of CR. Based on previous studies, we tried to describe and illustrate the mechanism of effective CR and its intensity in HF patients, which could be helpful in CR protocol development. Most importantly, further studies should aim to develop definitive and unified guidelines for CR in HF.

\section{Conclusions}

Cardiac Rehabilitation has confirmed efficacy in increased physical level of participation in home/work/ recreational activities, improved psychosocial well-being, functional independence, prevention of disability, longterm adherence to maintaining physically active lifestyle, improved cardiopulmonary fitness, strength, muscle endurance, and flexibility, reduced cardiovascular events risk and risk of mortality. Interestingly, individual protocols of the above reviewed $\mathrm{CR}$ trials varied in terms of intensity and type of physical exercise (aerobic vs anaerobic) used, what in turn implies a question about the most effective CR protocol.

If the patient is free from contradictions to $C R$, then the first step of effective $C R$ is to examine patients subjective ability to undertake aerobic exercise, which could be done by ergospirometry test most favourably, which is a gold-standard in aerobic capacity assessment. Moreover, maximal strength and spirometry tests could be additionally assessed. Then, based on the results of above mentioned tests, patient ability and/or the need to take part in the aerobic training, resistance training and/or respiratory training could be assessed as well as the intensity of the training protocol could be established.

Frequency of training-bouts in CR protocol in HF patients were from 3 to 7 days per week with 3 to 5 days per week being most common. Intensity ranged from 40 to $80 \% \mathrm{VO}_{2}$ max and it is recommended to start at a lower range of intensity and progress to the higher one. Progression to $80 \% \mathrm{VO}_{2}$ max should be done in hospitals. Interestingly, low intensity $\left(40 \% \mathrm{VO}_{2}\right.$ max) for 8 wk protocol can be effective in some patients. Intensity presented as rating of perceived exertion (RPE) with a range of 9 to 14 on a Borg scale of 6 to 20 being acceptable. Duration of single 
bout of exercise is advised to be 5 to 10 minutes and progressing up to 20 to 60 minutes per session with proper warm-up and cool-down periods included.

\section{Acknowledgments}

We would like to thank Professor Aleksander Goch for inspiration to writing this manuscript.

\section{References}

Ades, P.A., Keteyian, S.J., Balady, G.J., Houston-Miller, N., Kitzman, D.W., Mancini, D.M., Rich, M.W. (2013). Cardiac rehabilitation exercise and self-care for chronic heart failure. JACC: Heart failure, 1 (6), 540-547.

Adsett, J., Mullins, R. (2010). Evidence based guidelines for exercise and chronic heart failure. Quenssland.

Alves, A.J., Ribeiro, F., Goldhammer, E., Rivlin, Y., Rosenschein, U., Viana, J.L., ..., Oliveira, J. (2012). Exercise training improves diastolic function in heart failure patients. Medicine \& Science in Sports \& Exercise, 44 (5), 776-785.

Anderson, L., Oldridge, N., Thompson, D.R., Zwisler, A.D., Rees, K., Martin, N., Taylor, R.S. (2016). Exercise-based cardiac rehabilitation for coronary heart disease: Cochrane systematic review and meta-analysis. Journal of the American College of Cardiology, 67 (1), 1-12.

Balady, G.J., Ades, P.A., Bittner, V.A., Franklin, B.A., Gordon, N.F., Thomas, R.J., ..., Yancy, C.W. (2011). Referral, enrollment, and delivery of cardiac rehabilitation/secondary prevention programs at clinical centers and beyond. Circulation, 124 (25), $2951-2960$.

Belardinelli, R., Georgiou, D., Cianci, G., Purcaro, A. (1999). Randomized, controlled trial of long-term moderate exercise training in chronic heart failure. Circulation, 99 (9), 1173-1182.

Belardinelli, R., Georgiou, D., Scocco, V., Barstow, T.J., Purcaro, A. (1995). Low intensity exercise training in patients with chronic heart failure. Journal of the American College of Cardiology, 26 (4), 975-982.

Benito, B., Nattel, S. (2009). Exercise training as a treatment for heart failure: potential mechanisms and clinical implications. The Journal of physiology, 587 (21), 5011-5013.

Blumenthal, J.A., Sherwood, A., Smith, P.J., Watkins, L., Mabe, S., Kraus, W.E., ..., Hinderliter, A. (2016). Enhancing cardiac rehabilitation with stress management training: a randomized clinical efficacy trial. Circulation, 115.

Braith, R.W., Welsch, M.A., Feigenbaum, M.S., Kluess, H.A., Pepine, C.J. (1999). Neuroendocrine activation in heart failure is modified by endurance exercise training. Journal of the American College of Cardiology, 34 (4), 1170-1175.

Coats, A.J., Adamopoulos, S., Radaelli, A., McCance, A., Meyer, T.E., Bernardi, L., ..., Forfar, C.O.N.W.A.Y. (1992). Controlled trial of physical training in chronic heart failure. Exercise performance, hemodynamics, ventilation, and autonomic function. Circulation, 85 (6), 2119-2131.

Corra, U., Mezzani, A., Bosimini, E., Giannuzzi, P. (2004). Cardiopulmonary exercise testing and prognosis in chronic heart failure*: a prognosticating algorithm for the individual patient. CHEST Journal, 126 (3), 942-950.

Edelmann, F., Gelbrich, G., Düngen, H.D., Fröhling, S., Wachter, R., Stahrenberg, R., ..., Herrmann-Lingen, C. (2011). Exercise training improves exercise capacity and diastolic function in patients with heart failure with preserved ejection fraction: results of the ExDHF (Exercise training in Diastolic Heart Failure) pilot study. Journal of the American College of Cardiology, 58 (17), 1780-1791.

Francis, D.P., Shamim, W., Davies, L.C., Piepoli, M.F., Ponikowski, P., Anker, S.D., Coats, A.J.S. (2000). Cardiopulmonary exercise testing for prognosis in chronic heart failure: continuous and independent prognostic value from $\mathrm{VE} / \mathrm{VCO}_{2}$ slope and peak $\mathrm{VO}_{2}$. European Heart Journal, 21 (2), 154-161.

Giannuzzi, P., Tavazzi, L., Meyer, K., Perk, J., Drexler, H., Dubach, P., ..., Meyers, J. (2001). Recommendations for exercise training in chronic heart failure patients. European Heart Journal, 22 (2), 125-135.

Gunstad, J., MacGregor, K.L., Paul, R.H., Poppas, A., Jefferson, A.L., Todaro, J.F., Cohen, R.A. (2005). Cardiac rehabilitation improves cognitive performance in older adults with cardiovascular disease. Journal of cardiopulmonary rehabilitation, 25 (3), 173.

Hambrecht, R., Gielen, S., Linke, A., Fiehn, E., Yu, J., Walther, C., ..., Schuler, G. (2000). Effects of exercise training on left ventricular function and peripheral resistance in patients with chronic heart failure: a randomized trial. Jama, 283 (23), 3095-3101.

Keast, M.L., D’Angelo, M.E.S., Nelson, C.R., Turcotte, S.E., McDonnell, L.A., Nadler, R.E., .., Reid, R.D. (2013). Randomized trial of Nordic walking in patients with moderate to severe heart failure. Canadian journal of cardiology, 29 (11), 1470-1476. 
Legallois, D., Belin, A., Nesterov, S.V., Milliez, P., Parienti, J.J., Knuuti, J., ..., Manrique, A. (2016). Cardiac rehabilitation improves coronary endothelial function in patients with heart failure due to dilated cardiomyopathy: A positron emission tomography study. European journal of preventive cardiology, 23 (2), 129-136.

Lipkin, D.P., Scriven, A.J., Crake, T., Poole-Wilson, P.A. (1986). Six minute walking test for assessing exercise capacity in chronic heart failure. Br Med J (Clin Res Ed), 292 (6521), 653-655.

Montemezzo, D., Fregonezi, G.A., Pereira, D.A., Britto, R.R., Reid, W.D. (2014). Influence of inspiratory muscle weakness on inspiratory muscle training responses in chronic heart failure patients: a systematic review and meta-analysis. Archives of physical medicine and rehabilitation, 95 (7), 1398-1407.

O'Connor, C.M., Whellan, D.J., Lee, K.L., Keteyian, S.J., Cooper, L.S., Ellis, S.J., ..., Rendall, D.S. (2009). Efficacy and safety of exercise training in patients with chronic heart failure: HF-ACTION randomized controlled trial. Jama, 301 (14), 1439-1450.

Osman, A.F., Mehra, M.R., Lavie, C.J., Nunez, E., Milani, R.V. (2000). The incremental prognostic importance of body fat adjusted peak oxygen consumption in chronic heart failure. Journal of the American College of Cardiology, 36 (7), 2126-2131.

Piepoli, M.F., Conraads, V., Corra, U., Dickstein, K., Francis, D.P., Jaarsma, T., ..., Anker, S.D. (2011). Exercise training in heart failure: from theory to practice. A consensus document of the Heart Failure Association and the European Association for Cardiovascular Prevention and Rehabilitation. European journal of heart failure, 13 (4), 347-357.

Piepoli, M., Davos, C., Francis, D.P., Coats, A.J. (2004). Exercise training meta-analysis of trials in patients with chronic heart failure (ExTraMATCH).

Piña, I.L., Apstein, C.S., Balady, G.J., Belardinelli, R., Chaitman, B.R., Duscha, B.D., ..., Sullivan, M.J. (2003). Exercise and heart failure. Circulation, 107 (8), 1210-1225.

Roomi, J., Johnson, M.M., Waters, K., Yohannes, A., Helm, A., Connolly, M.J. (1996). Respiratory rehabilitation, exercise capacity and quality of life in chronic airways disease in old age. Age and Ageing, 25 (1), 12-16.

Rostagno, C., Olivo, G., Comeglio, M., Boddi, V., Banchelli, M., Galanti, G., Gensini, G.F. (2003). Prognostic value of 6-minute walk corridor test in patients with mild to moderate heart failure: comparison with other methods of functional evaluation. European journal of heart failure, 5 (3), 247-252.

Selig, S.E., Levinger, I., Williams, A.D., Smart, N., Holland, D.J., Maiorana, A., ..., Hare, D.L. (2010). Exercise \& Sports Science Australia Position Statement on exercise training and chronic heart failure. Journal of Science and Medicine in Sport, 13 (3), $288-294$.

Shimiaie, J., Sherez, J., Aviram, G., Megidish, R., Viskin, S., Halkin, A., ..., Topilsky, Y. (2015). Determinants of effort intolerance in patients with heart failure: combined echocardiography and cardiopulmonary stress protocol. JACC: Heart Failure, 3 (10), 803-814.

Smarż, K. (2008). Cardiac rehabilitation in various clinical situation-phases, indications, contraindications, risks and safety issues. Postępy Nauk Medycznych.

Troosters, T., Gosselink, R., Decramer, M. (1999). Six minute walking distance in healthy elderly subjects. European Respiratory Journal, 14 (2), 270-274.

Uddin, J., Zwisler, A.D., Lewinter, C., Moniruzzaman, M., Lund, K., Tang, L.H., Taylor, R.S. (2016). Predictors of exercise capacity following exercise-based rehabilitation in patients with coronary heart disease and heart failure: a meta-regression analysis. European journal of preventive cardiology, 23 (7), 683-693.

Weber, K.T., Janicki, J.S. (1985). Cardiopulmonary exercise testing for evaluation of chronic cardiac failure. The American journal of cardiology, 55 (2), A22-A31.

Wisløff, U., Støylen, A., Loennechen, J.P., Bruvold, M., Rognmo, Ø., Haram, P.M., ..., Videm, V. (2007). Superior cardiovascular effect of aerobic interval training versus moderate continuous training in heart failure patients. Circulation, 115 (24), 3086-3094.

Cite this article aS: Kujawska, A., Perkowski, R., Skierkowska, N., Topka, W., Gajos, M., Androsiuk-Perkowska, J., Cieślińska, A., Przybysz, B., Kwolik, D. Siekacz, D. Rybarczyk, D., Kujawski, S. (2018). Cardiac Rehabilitation in Heart Failure. Part II. Does Higher Intensity Means Better Outcome? Central European Journal of Sport Sciences and Medicine, 2 (22), 23-32. DOI: 10.18276/ cej.2018.2-03. 